\title{
Mars Microprobe Entry Analysis
}

\author{
Robert D. Braun* \\ NASA Langley Research Center \\ Hampton, VA 23681-0001 \\ (757) 864-4507 \\ r.d.braun@larc.nasa.gov
}

\author{
Robert A. Mitcheltree ${ }^{\dagger}$ \\ NASA Langley Research Center \\ Hampton, VA 23681-0001 \\ (757) 864-4382 \\ r.a.mitcheltree@larc.nasa.gov
}

\author{
F. McNeil Cheatwood \\ Vigyan Inc. \\ Hampton, VA 23666-1325 \\ (757) 864-2984 \\ f.m.cheatwood@larc.nasa.gov
}

Abstract-The Mars Microprobe mission will provide the first opportunity for subsurface measurements, including water detection, near the south pole of Mars. In this paper, performance of the Microprobe aeroshell design is evaluated through development of a six-degreeof-freedom (6-DOF) aerodynamic database and flight dynamics simulation. Numerous mission uncertainties are quantified and a Monte-Carlo analysis is performed to statistically assess mission performance. Results from this 6-DOF Monte-Carlo simulation demonstrate that, in a majority of the cases (approximately $2-\sigma$ ), the penetrator impact conditions are within current design tolerances. Several trajectories are identified in which the current set of impact requirements are not satisfied. From these cases, critical design parameters are highlighted and additional system requirements are suggested. In particular, a relatively large angle-of-attack range near peak heating is identified.

\section{Table Of Contents}

\section{INTRODUCTION \\ 2. NOMENClature \\ 3. IMPACT REQUIREMENTS \\ 4.1 Aeroshell Selection \\ 4.2 AERODYNAMICS \\ 4.3 Atmos. Flight Dynamics \\ 5.1 ImPaCt Sizing \\ 5.2 Monte-Carlo Simulation \\ 6. Conclusions}

${ }^{*}$ Space Systems and Concepts Division, Mail Stop 365

${ }^{\dagger}$ Aero and Gas Dynamics Division, Mail Stop 408A

\section{INTRODUCTION}

The objective of NASA's New Millennium program is to demonstrate and flight qualify technology elements required for the science missions of the next century [1]. The program's second flight project, Deep Space Two (DS2 ) is focused on the design of two small Mars entry probes. As a result, DS-2 is often referred to as the Mars Microprobe mission. This proof-of-concept system is intended to demonstrate key elements of future network science missions [2,3]. Attached to the cruise stage of the Mars 98 Surveyor Lander, these two Microprobe vehicles will be launched to Mars by a Delta II rocket in January 1999, arriving in December 1999. Each of these Microprobe capsules houses instrumented penetration devices designed to analyze the subsurface layers by performing soil sampling and water detection. On impact, the penetrators are designed to pierce their protective aeroshells, driving this subsurface instrumentation 0.3-2.0 m below the surface. Subsurface data will be relayed back to Earth through a link with the Mars Global Surveyor orbiter (September 1997 Mars arrival).

The entry, descent, and impact (EDI) phase of the DS-2 mission begins as the two capsules are mechanically separated from the cruise stage [4]. This event is preceded by separation of the Mars 98 Lander from the cruise stage (approximately $1.5 \mathrm{~s}$ earlier). As a result of (1) the brief period between these two separation events, (2) the lack of control of the cruise-stage after the 98 Lander separation, and (3) geometric mounting 
constraints which do not allow the Microprobe vehicles to be aligned with the flight path, the capsules will separate in an unknown angular orientation with non-zero angular rates. Stable flight of the Microprobe vehicles must be achieved passively, and maintained until surface impact.

Design of the DS-2 entry probes is complicated by several unique aerodynamic challenges. The vehicles must possess enough aerodynamic stability to achieve passive re-orientation from an arbitrary initial motion prior to peak heating. Since stable flight at impact is required, the supersonic and transonic dynamic stability problems which have plagued other entry missions $[5,6,7]$ must also be mitigated. Additionally, the penetrators must be protected from the intense aerothermodynamic environment of a $7.0 \mathrm{~km} / \mathrm{s}$ Mars entry and satisfy a stringent set of surface impact constraints.

In this paper, the criteria used to select the aeroshell geometry are presented. After review of the aeroshell shape and mass properties, compilation of the Microprobe aerodynamic database is discussed. This database is compiled from past studies, computational fluid dynamic calculations, and ground-based test data. Development of a six-degree-of-freedom (6-DOF) Monte-Carlo trajectory simulation for Microprobe EDI is also presented. Results from this 6-DOF Monte-Carlo simulation are used to statistically assess the effect of combinatorial variations in the significant EDI parameters.

\section{NomenClature}

A reference aerodynamic surface area, $\mathrm{m}^{2}$

b yaw/roll reference length, $\mathrm{m}$

c pitch reference length, $m$

C aerodynamic force or moment coefficient

g Mars surface slope, deg

Kn Knudsen number

$\mathrm{m}$ mass, $\mathrm{kg}$

M Mach number

I body-axis moments of inertia, $\mathrm{kg}-\mathrm{m}^{2}$

$\dot{q} \quad$ stagnation-point heat rate, $\mathrm{W} / \mathrm{cm}^{2}$

$$
\begin{array}{ll}
\mathrm{Q} & \text { dynamic pressure, } \mathrm{N} / \mathrm{m}^{2} \\
\mathrm{~V} & \text { velocity, m/s } \\
\alpha & \text { angle-of-attack, deg } \\
\beta & \text { ballistic coefficient }\left(\frac{\mathrm{m}}{C_{D} A}\right) \mathrm{kg} / \mathrm{m}^{2} \\
\gamma & \text { flight-path or incidence angle, deg }
\end{array}
$$

\begin{tabular}{ll}
\multicolumn{2}{l}{ Subscripts } \\
a & relative to the atmosphere \\
$\mathrm{A}$ & axial force \\
$\mathrm{D}$ & drag force \\
$\mathrm{l}$ & static rolling moment \\
$\mathrm{m}$ & static pitching moment \\
$\mathrm{mq}$ & dynamic pitching moment \\
$\mathrm{n}$ & static yawing moment \\
$\mathrm{N}$ & normal force \\
$\mathrm{nr}$ & dynamic yawing moment \\
$\mathrm{p}$ & penetrator \\
$\mathrm{r}$ & relative to the horizon \\
$\mathrm{t}$ & total \\
$\mathrm{Y}$ & side force
\end{tabular}

\section{Surface Impact Requirements}

The penetrators have been designed to operate properly under a range of impact conditions. Mission success demands that the EDI system meet several surface impact constraints. Three- $\sigma$ requirements on surface impact velocity $\left(140 \leq V_{r} \leq 200 \mathrm{~m} / \mathrm{s}\right)$, penetration angleof-attack $\left(0 \leq \alpha_{p} \leq 10\right.$ degrees $)$, and penetration incidence angle $\left(\left|\gamma_{p}\right| \leq 20\right.$ degrees $)$ have been specified [4]. These requirements are currently being validated through a rigorous ground-testing program.

The dynamics of the surface impact event are illustrated in Fig. 1. The Microprobe aeroshell, local horizon, and local surface slope are shown, along with the velocities with respect to the ground $\left(V_{r}\right)$ and atmosphere $\left(V_{a}\right)$. By convention, the flight-path angles shown are negative. Atmospheric winds cause the difference between $V_{r}$ and $V_{a}$. Total angle-of-attack ( $\alpha_{t}$ in Fig. 1) is defined as the angle between the vehicle's axis of symmetry and $V_{a}$.

During flight, the forces on the aeroshell are a function of the relationship between the vehicle 


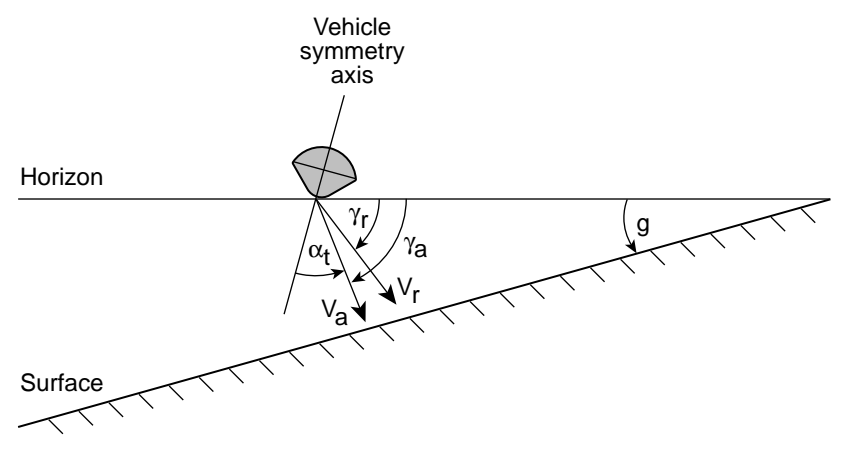

Figure 1. Definition of Mars Microprobe surface impact angles.

and the atmospheric velocity vector $\left(\alpha_{t}\right.$ and $\left.V_{a}\right)$. However, at impact, the orientation of the Microprobe payload relative to the surface is of significance. The penetration angle-of-attack and incidence angle are defined as:

$$
\begin{aligned}
\alpha_{p} & =\alpha_{t}+\left(\gamma_{a}-\gamma_{r}\right) \\
\gamma_{p} & =\gamma_{r}+90^{\circ}-g
\end{aligned}
$$

As discussed below, the surface impact velocity and incidence angle constraints may be achieved through the selection of the appropriate ballistic coefficient (see Section 5); whereas, satisfaction of the impact angle-of-attack constraint is a function of the vehicle's aerodynamic stability (geometry and center-of-gravity location). Aerodynamic design of the Microprobe capsules is presented in Section 4. The variance in each of the significant impact parameters as well as statistical data regarding the aeroshell heating environment is presented in Section 5.

\section{ANALYSIS}

\section{Aeroshell Selection}

Selection of the aeroshell for Mars Microprobe requires consideration of the unique objectives of the mission. A passive enclosure is required to safely deliver the penetrator payload through entry to impact with the surface. The aeroshell must decelerate the vehicle during its descent to a prescribed impact velocity. It must possess sufficient stability to correct any initial tumbling motion to forward-facing flight early in the trajectory and maintain that orientation within small tolerances until impact. Finally, it must protect the payload from intense aerodynamic heating. To meet these objectives a 45-degree half-angle cone with rounded nose and shoulders is selected for the forebody. The afterbody is hemispherical with its center at the vehicle's center-of-gravity location.

Blunted 45-degree sphere-cones were used for the successful Pioneer-Venus and Galileo missions [8]. Both of these missions entered atmospheres much denser than Mars. For the Mars entries of Viking and Mars Pathfinder, 70-degree sphere-cones with a zero angle-ofattack drag coefficient near 1.7 (versus the 45degree cone value of 1.05) were selected [9]. Choice of cone angle calls for a compromise of drag, stability and packaging. Blunter cones exhibit more drag per surface area; sharper cones possess more stability. Viking and Pathfinder make use of high drag aeroshells since both of these entries required deceleration of much heavier spacecraft at sufficiently high altitudes for parachute deployment. In contrast, the Mars Microprobe vehicles are more than two orders of magnitude lighter and must impact the surface at a high velocity $(140-200 \mathrm{~m} / \mathrm{s})$. Additionally, each Microprobe capsule requires the highest possible aerodynamic stability to recover quickly from any initial tumbling motion.

The degree of nose bluntness has little effect on the drag coefficient for a 45-degree halfangle cone, although increased bluntness does slightly decrease static stability. On the other hand, increased bluntness decreases the stagnation point heat rate during the hypersonic portion of the trajectory. Selecting the appropriate degree of nose bluntness is a compromise of these factors. For Microprobe, a nose radius equal to half of the vehicle's overall base radius is an acceptable value. This is the same ratio used in the Pioneer-Venus and Galileo entry probes $[7,10,11]$. Similarly, rounding the vehicle's shoulders is performed to decrease local heating. Rounding the shoulders decreases both drag and stability. Again, the Pioneer-Venus value of shoulder radius equal to one tenth the 
nose radius is specified for Microprobe. Although it is possible to optimize the amount of nose and shoulder rounding for the specific Microprobe mission, the selection of previously used ratios appears adequate and also allows the use of an extensive body of existing aerodynamic test and flight data.

Selection of the hemispherical afterbody is based on the Planetary Atmosphere Experiments Test (PAET) probe [12]. The hemispherical afterbody specified for Microprobe serves two purposes. First, since the vehicle may be tumbling initially, it may encounter the atmosphere while traveling backwards. A hemispherical afterbody with center at the vehicle's center-of-gravity is not stable in this orientation and will foster rotation to a forward facing attitude. Second, this afterbody has been shown to decrease the dynamic instability observed in blunt vehicles traversing the transonic flight regime [13]. Regarding backwards stability, it is of interest to note that Pioneer-Venus, Galileo, Viking and Mars Pathfinder were all hypersonically stable in a backwards orientation. To prevent this occurrence, each entry vehicle was oriented nose-first and spin-stabilized to assure a forward-facing attitude at the atmospheric interface. Spin stabilization is not an option for Microprobe; however, the hemispherical afterbody assures the vehicle will not trim in a backwards-facing attitude.

The geometry of the Mars Microprobe aeroshell is depicted in Fig. 2. As shown, a 45-degree sphere cone with nose radius of $0.0875 \mathrm{~m}$, shoulder radius of $0.00875 \mathrm{~m}$, and maximum radius of $0.175 \mathrm{~m}$ has been selected. The afterbody shape is a hemispherical section with radius of $0.183 \mathrm{~m}$ centered about the vehicle's center-ofgravity. The center-of-gravity is located 0.0902 $\mathrm{m}$ aft of the nose on the vehicle's symmetry axis.

\section{Aerodynamics}

The Mars Microprobe aerodynamic database was derived from a combination of computational fluid dynamic (CFD) calculations and

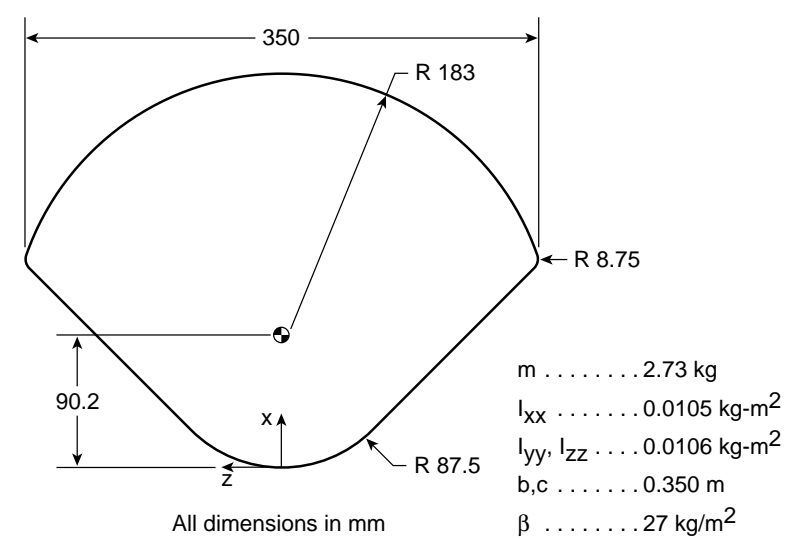

Figure 2. Mars Microprobe aeroshell geometry and mass properties.

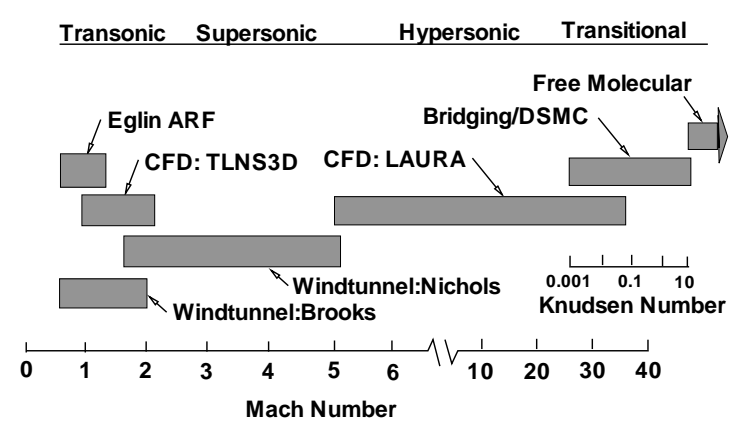

Figure 3. Sources used to assemble Mars Microprobe aerodynamic database.

ground-based test data. A detailed description of the vehicle's aerodynamic characteristics is provided in Ref. [14]. Sources of the static aerodynamic predictions are illustrated in Fig. 3. Free molecular and Direct Simulation Monte Carlo (DSMC) computations were performed to characterize the rarefied and transitional flow regimes. These results were supplemented by thermochemical nonequilibrium computational fluid dynamic calculations obtained with the Langley Aerothermodynamic Upwind Relaxation Algorithm (LAURA in Fig. 3) in the continuum hypersonic flow regime. This analysis tool was extensively used in the prediction of the Mars Pathfinder aerodynamics [15]. PioneerVenus wind tunnel data was used in the supersonic, transonic, and subsonic regimes [16, 17]. 
Validation and extrapolation of these existing results was made possible through additional computational solutions obtained in the transonic and subsonic flight regimes with the Thin-Layer Navier-Stokes 3-Dimensional program [18] (TLNS3D in Fig. 3).

Dynamic damping coefficients were extracted from Pioneer-Venus and Viking wind tunnel test data $[5,6,7]$. In addition, transonic ballistic range data was produced on a Microprobe model with the correct center-of-gravity location $[19,20]$. Dynamic stability estimates could not be obtained computationally within the time constraints of the present analysis. Because of the transonic dynamic instability problems which have plagued other entry vehicle designs, additional data is being gathered in a pressurized facility in which the flight Reynolds number can be duplicated [19].

To produce a cohesive database from these diverse sources, modification of the original data set was required [21]. A bridging function (shaped by the DSMC results) was used in the transitional region between the free molecular and continuum results. Explicit calculation of the transitional aerodynamics by DSMC methods, although possible, is computationally prohibitive. Instead, selected DSMC results were used to anchor and shape the bridging function. This function provides a smooth variation of the vehicle's aerodynamic characteristics based on the free molecular and continuum hypersonic computations.

Within the database [21], the continuum hypersonic aerodynamics were assumed to vary with angle of attack in a similar manner to that predicted by Newtonian flow. This Newtonian variation was then scaled to reproduce specific LAURA computations obtained at 0 and 10-degrees angle of attack. The supersonic and transonic wind tunnel data overlapped, so the two sets were blended in the Mach number region between 1.65 and 2.16. Similarly, the Pioneer-Venus and Viking dynamics data were blended in the Mach number region between 1.2

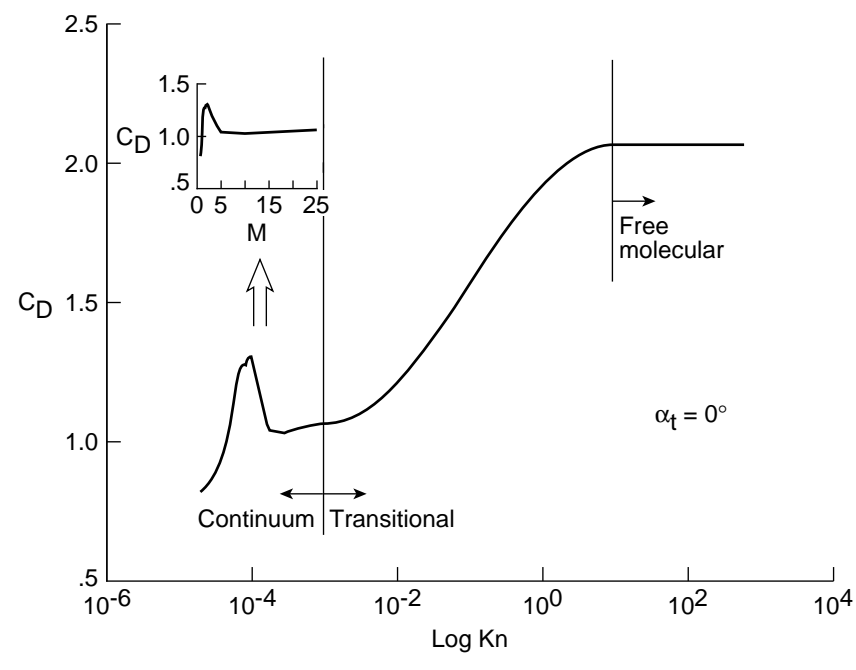

Figure 4. Mars Microprobe 0-degree angle-ofattack drag coefficient.

and 1.3. Finally, to account for small differences in the aeroshell geometry, the axial force wind tunnel values were scaled to match the computational results.

Early versions of the aerodynamics routine used simple linear interpolation, providing valuecontinuity between segments. Although a twice-differentiable database was sought, providing this level of continuity at the data points resulted in unacceptable behavior between the data. As a compromise, an overlapping parabola technique, which provides slopecontinuity, was used. As the FORTRAN routine was developed, care was taken to minimize memory overhead. Furthermore, since the routine is called many times by 6-DOF POST, an effort was made to create a computationally efficient algorithm. For a given flight condition and vehicle angular orientation, the database provides estimates of $\mathrm{C}_{A}, \mathrm{C}_{N}, \mathrm{C}_{Y}, \mathrm{C}_{m}, \mathrm{C}_{n}, \mathrm{C}_{l}$, $\mathrm{C}_{m q}$, and $\mathrm{C}_{n r}$ for use in the 6-DOF trajectory simulation [21].

The 0-degree angle-of-attack Microprobe drag coefficient is shown in Fig. 4 as a function of Knudsen (Kn) and Mach (M) numbers. Knudsen number is defined as the ratio of the gas' mean free path to the vehicle's diameter. This similarity parameter is used as the independent variable in the rarefied and transi- 
tional aerodynamic regimes. Initially, Kn will be large. For values larger than 10, the aerodynamic forces are computed solely from the free molecular flow solutions. Free molecular flow assumes there are no collisions between gas molecules in the flow field. Unlike hypersonic continuum aerodynamics (where forces exerted on the body are essentially the integrated effect of surface pressures alone), free molecular flow aerodynamics contain a significant shear stress contribution. As the entry proceeds into the upper atmosphere, both the mean free path and Knudsen number decrease and collisions between particles must be taken into account. In this regime, where $0.001<K n<10$, the aerodynamics are computed from the DSMCanchored bridging function.

As lower altitudes are reached (below $55 \mathrm{~km}$ altitude for Microprobe), the Knudsen number drops below 0.001 and the continuum methods are used to compute vehicle aerodynamics. Here, Mach number is the appropriate aerodynamic similarity parameter. Fig. 4 shows that drag coefficient (at a given angle of attack) is approximately constant above Mach 5 . The increase in drag coefficient supersonically, is a result of the sonic line shifting from the nose region to the shoulder region of the aeroshell between Mach 5 and 2. This shift has a significant impact on the pressure distribution causing axial force (equivalent to drag at 0-degree angle-of-attack) to increase while normal force and moment coefficient decrease. Transonically, drag coefficient decreases. Here the data of Refs. $[17,20]$ and the TLNS3D computational solutions are used. The axial force data of Ref. [17] is decreased to account for the Microprobe configuration's large hemispherical afterbody.

\section{Atmospheric Flight Dynamics}

Six-degree-of-freedom (6-DOF) trajectory analysis is performed using the Program to Optimize Simulated Trajectories (POST) [22]. This program has been used previously in the development of the Mars Pathfinder entry, descent, and landing (EDL) strategy [23, 24]. Six-DOF POST is also being used by the Pathfinder EDL operations team $[25,26]$. In the present study, POST is used to numerically integrate the 6DOF equations of motion from a given entry state to surface impact. An eighth-order RungeKutta integration technique is employed [27]. The Microprobe aerodynamic database as well as Mars atmospheric, gravitational, and surface models are inputs to the simulation. Atmospheric modeling for this mission is hampered by the lack of surface measurements for the southern hemisphere of Mars (the target impact site is $73-77$ degrees South latitude). Using projected data obtained from the Viking landers and a global circulation model, Zurek and Richardson have constructed nominal and perturbed atmospheric profiles [28]. These models are used in the current simulation.

In the present analysis, uncertainties are applied in all simulation model inputs. These uncertainties arise from numerous sources including (1) technology limitations (e.g., current interplanetary navigation or mass-balance accuracies), (2) a lack of knowledge concerning the Mars atmosphere, (3) computational or measurement uncertainty associated with the aerodynamic analyses, and (4) unknown separation orientation and angular rate. Therefore, in this analysis, an attempt was made to quantify and model the degree of uncertainty in each of 29 major parameters.

The uncertainty range attributed to each of these parameters is listed in Table 1. For a parameter with more than one variance (e.g., aerodynamics or winds), the uncertainty is estimated using linear interpolation between the regions given in Table 1. Gaussian distributions are sampled for most parameters. However, the initial orientation, center-of-gravity offset quadrant, and wind direction quadrant are determined from uniform distributions. The topography variation is modeled by a non-symmetric Gaussian distribution centered at $5 \mathrm{~km}$. This distribution is illustrated in Fig. 5. 
Table 1. 6-DOF Monte-Carlo variables.

\begin{tabular}{|c|c|c|}
\hline EDI Parameter & $\begin{array}{l}\text { Nominal } \\
\text { Value }\end{array}$ & $\begin{array}{c}3-\sigma \\
\text { Variance }\end{array}$ \\
\hline Initial state, $\gamma, \operatorname{deg}$ & -13.25 & \pm 0.4 \\
\hline Initial $\alpha_{t}, \operatorname{deg}$ & 90.0 & \pm 90.0 \\
\hline Initial pitch rate, $\mathrm{deg} / \mathrm{s}$ & 6.0 & \pm 5.0 \\
\hline Initial yaw rate, $\mathrm{deg} / \mathrm{s}$ & 6.0 & \pm 5.0 \\
\hline Initial roll rate, $\mathrm{deg} / \mathrm{s}$ & 6.0 & \pm 5.0 \\
\hline $\mathrm{X}$-axis cg position, $\mathrm{mm}$ & 90.2 & \pm 5.0 \\
\hline $\mathrm{X}$-axis cg offset, $\mathrm{mm}$ & 0.0 & \pm 1.0 \\
\hline Mass, kg & 2.73 & \pm 0.273 \\
\hline $\mathrm{I}_{x x}, \mathrm{~kg}-\mathrm{m}^{2}$ & 0.0106 & \pm 0.0003 \\
\hline $\mathrm{I}_{y y}, \mathrm{I}_{z z}, \mathrm{~kg}-\mathrm{m}^{2}$ & 0.0105 & \pm 0.0003 \\
\hline $\mathrm{I}_{x y}, \mathrm{I}_{x z}, \mathrm{I}_{y z}, \mathrm{~kg}-\mathrm{m}^{2}$ & 0.0 & \pm 0.0003 \\
\hline $\mathrm{C}_{A}, \mathrm{Kn} \geq 0.1$ & See Fig. 4 & $\pm 10 \%$ \\
\hline $\mathrm{C}_{N}, \mathrm{Kn} \geq 0.1$ & See Ref. [14] & \pm 0.10 \\
\hline $\mathrm{C}_{m}, \mathrm{Kn} \geq 0.1$ & See Ref. [14] & \pm 0.006 \\
\hline $\mathrm{C}_{A}, \mathrm{Kn}<0.1, \mathrm{M} \geq 10$ & See Fig. 4 & $\pm 2 \%$ \\
\hline $\mathrm{C}_{N}, \mathrm{Kn}<0.1, \mathrm{M} \geq 10$ & See Ref. [14] & \pm 0.05 \\
\hline $\mathrm{C}_{m}, \mathrm{Kn}<0.1, \mathrm{M} \geq 10$ & See Ref. [14] & \pm 0.003 \\
\hline $\mathrm{C}_{A}, \mathrm{Kn}<0.1, \mathrm{M} \leq 5$ & See Fig. 4 & $\pm 10 \%$ \\
\hline $\mathrm{C}_{N}, \mathrm{Kn}<0.1, \mathrm{M} \leq 5$ & See Ref. [14] & \pm 0.10 \\
\hline $\mathrm{C}_{m}, \mathrm{Kn}<0.1, \mathrm{M} \leq 5$ & See Ref. [14] & \pm 0.006 \\
\hline $\mathrm{C}_{m q}$ and $\mathrm{C}_{n r}, \mathrm{M} \geq 6$ & See Ref. [14] & $\pm 20 \%$ \\
\hline $\mathrm{C}_{m q}$ and $\mathrm{C}_{n r}, \mathrm{M} \leq 3$ & See Ref. [14] & $-50,+110 \%$ \\
\hline Density & See Ref. [28] & See Fig. 6 \\
\hline Temperature & See Ref. [28] & $\pm 150 \%$ \\
\hline Wind above $50 \mathrm{~km}$ & See Ref. [28] & See Fig. 7 \\
\hline Wind below $10 \mathrm{~km}$ & See Ref. [28] & See Fig. 7 \\
\hline Wind gust, m/s & 0.0 & \pm 30.0 \\
\hline Surface altitude, $\mathrm{km}$ & 5.0 & $-4,+1$ \\
\hline Surface slope, deg & 0.0 & \pm 5.0 \\
\hline
\end{tabular}

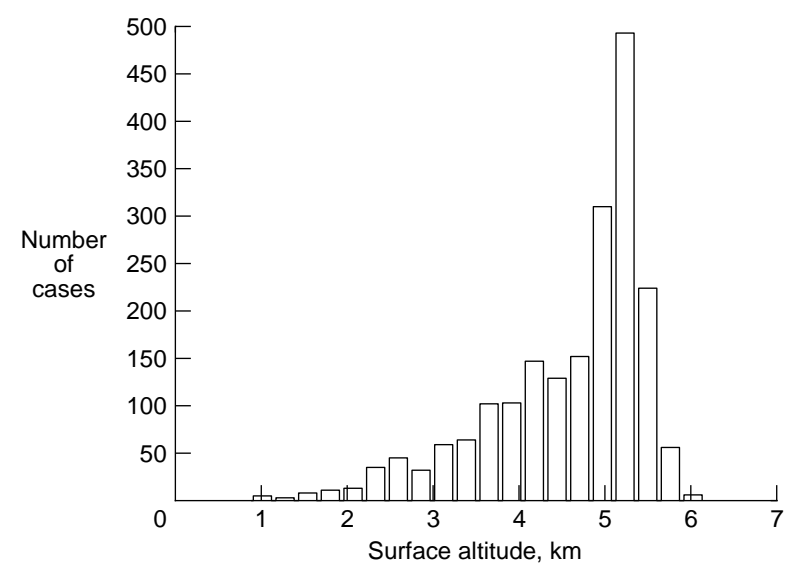

Figure 5. Impact altitude distribution.

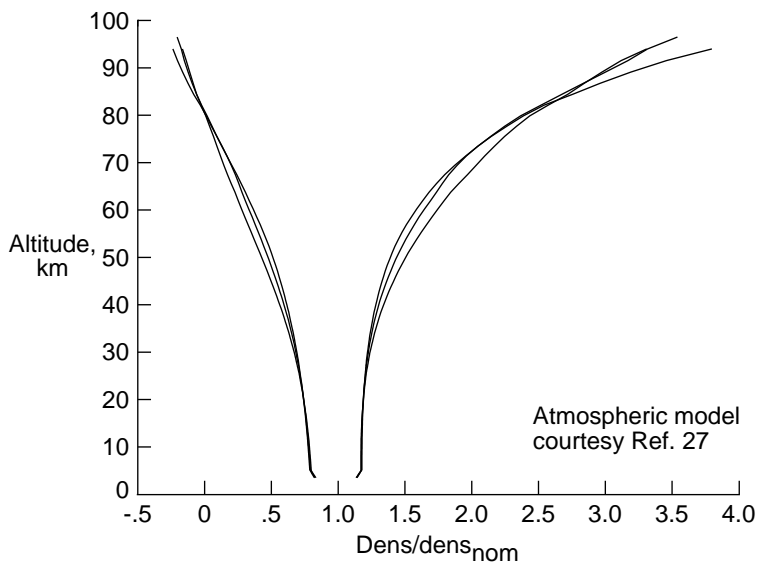

Figure 6. 3- $\sigma$ density variation used in the 6-DOF Monte-Carlo simulation.

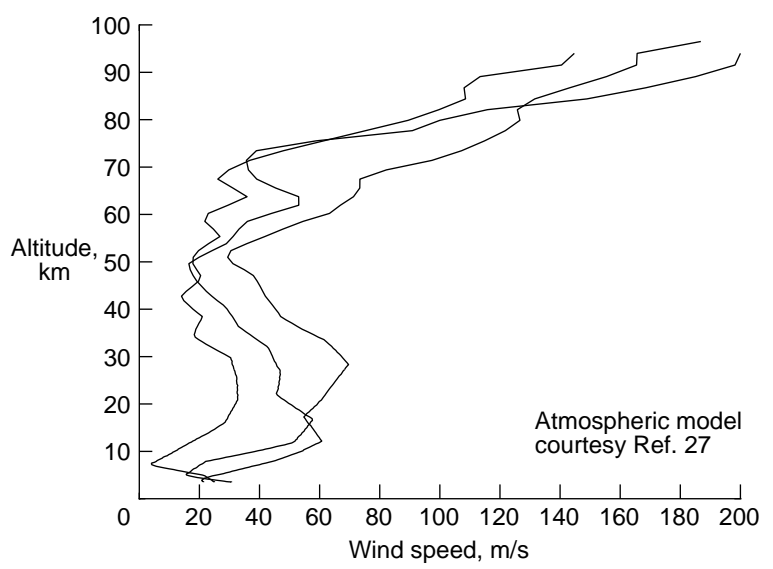

Figure 7. $3-\sigma$ wind profiles used in the 6 -DOF Monte-Carlo simulation.

The 3- $\sigma$ variances in atmospheric density and winds are shown in Figs. 6 and 7 . As illustrated in these figures, three atmospheric profiles with varying levels of visible column depth, or opacity $(0.05,0.2,0.5)$, are used in the present simulation. Within the Monte-Carlo simulation, these three nominal and perturbed atmospheric profiles are sampled evenly.

\section{Results And Discussion}

\section{Impact Sizing and Nominal Trajectory}

For zero angle-of-attack flight of the Microprobe capsules, the impact conditions are completely determined by ballistic coefficient $(\beta)$ and sur- 


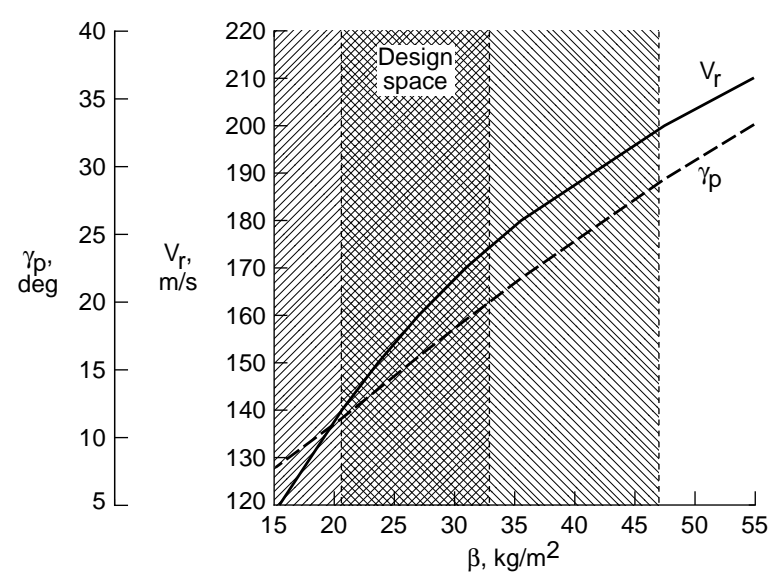

Figure 8. Mars Microprobe ballistic coefficient requirements, surface altitude $=5 \mathrm{~km}$.

face altitude. Assuming a surface slope of 5 degrees, an altitude of $5 \mathrm{~km}$, the mean density profile [28], and negligible wind speed, the following values are determined from Fig. 8. For an impact speed of $160 \mathrm{~m} / \mathrm{s}$, a ballistic coefficient of $27 \mathrm{~kg} / \mathrm{m}^{2}$ is required. Furthermore, the ballistic coefficient must be within the range of $20.6 \leq \beta \leq 47 \mathrm{~kg} / \mathrm{m}^{2}$ to satisfy the impact velocity criterion $\left(140 \leq V_{r} \leq 200 \mathrm{~m} / \mathrm{s}\right)$, and below $33.1 \mathrm{~kg} / \mathrm{m}^{2}$ to satisfy the penetration incidence angle constraint $\left(\left|\gamma_{p}\right| \leq 20\right.$ degrees $)$. Hence, the Microprobe design space is restricted such that $20.6 \leq \beta \leq 33.1 \mathrm{~kg} / \mathrm{m}^{2}$.

The design approach selected by the Mars Microprobe project office is to baseline the largest diameter aeroshell that does not adversely impact the Mars 98 Lander. This approach, which allows for modest mass growth, yields the 350 mm maximum diameter depicted in Fig. 2. As discussed earlier, a 45-degree sphere-cone has a continuum hypersonic $C_{D}$ of 1.05. Thus, for the nominal value of $\beta=27 \mathrm{~kg} / \mathrm{m}^{2}$, a Microprobe mass of $2.73 \mathrm{~kg}$ is required. Without ballast, the current system mass estimate is $2.63 \mathrm{~kg}$. This yields a mass margin of $3.8 \%$ at the nominal impact speed. As mentioned above, the impact constraints can be met with a ballistic coefficient as high as $\beta=33.1 \mathrm{~kg} / \mathrm{m}^{2}$; hence, the Microprobe heatshield is being sized for this value. At this upper limit of $\beta$, the current design mass margin is $27.1 \%$.

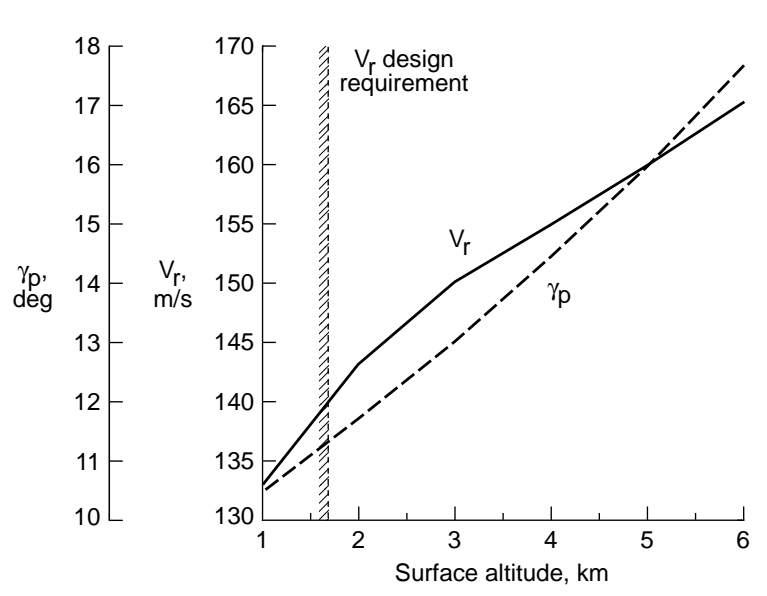

Figure 9. Effect of surface altitude on Microprobe impact conditions, $\beta=27 \mathrm{~kg} / \mathrm{m}^{2}$.

The impact of surface altitude on the Fig. 8 trade-space is shown in Fig. 9. For the impact site of interest, a surface altitude of 1 to $6 \mathrm{~km}$ above the Mars reference ellipsoid may be encountered [4]; however, a majority of this terrain is thought to be $5 \mathrm{~km}$ above the Mars reference ellipsoid (see Fig. 5). As shown in Fig. 9, impact velocity changes approximately $5 \mathrm{~m} / \mathrm{s}$ for each $\mathrm{km}$ of surface altitude and the penetration incidence angle decreases with surface altitude (at a rate of about $1.4 \mathrm{deg} / \mathrm{km}$ ). For $\beta=27$ $\mathrm{kg} / \mathrm{m}^{2}$, the impact velocity criterion is satisfied above $1.6 \mathrm{~km}$ altitudes; whereas the penetration incidence angle constraint is satisfied over the complete range of expected surface altitude.

The nominal Microprobe EDI trajectory is shown in Fig. 10. As shown, the atmospheric entry velocity is $6.9 \mathrm{~km} / \mathrm{s}$. The atmospheric interface is defined at a radius of $3522.2 \mathrm{~km}$ (surface altitude of $141.8 \mathrm{~km}$ ). The peak deceleration of 12.6 Earth g's is achieved at an altitude of $44.1 \mathrm{~km}$. Surface impact occurs roughly $290 \mathrm{sec}$ after atmospheric interface, at $160 \mathrm{~m} / \mathrm{s}$ (Mach 0.66). Fig. 11 shows that the peak stagnation-point heat rate of $160 \mathrm{~W} / \mathrm{cm}^{2}$ is achieved at approximately $80 \mathrm{sec}$ (altitude of $49.2 \mathrm{~km}$ ) and is followed by peak dynamic pressure $\left(3380 \mathrm{~N} / \mathrm{m}^{2}\right)$ at approximately $94 \mathrm{sec}$ into the EDI sequence. At impact, the integrated stagnation-point heat load is $7165 \mathrm{~J} / \mathrm{cm}^{2}$. 


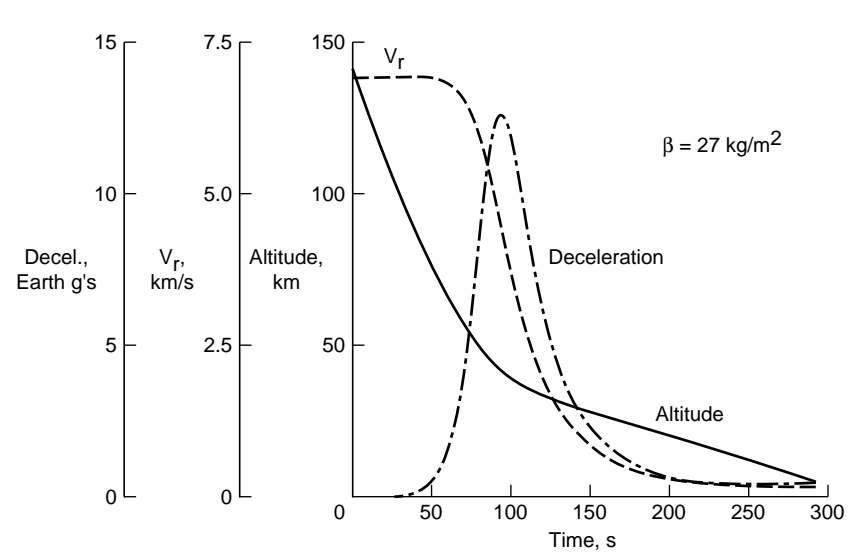

Figure 10. Mars Microprobe nominal trajectory.

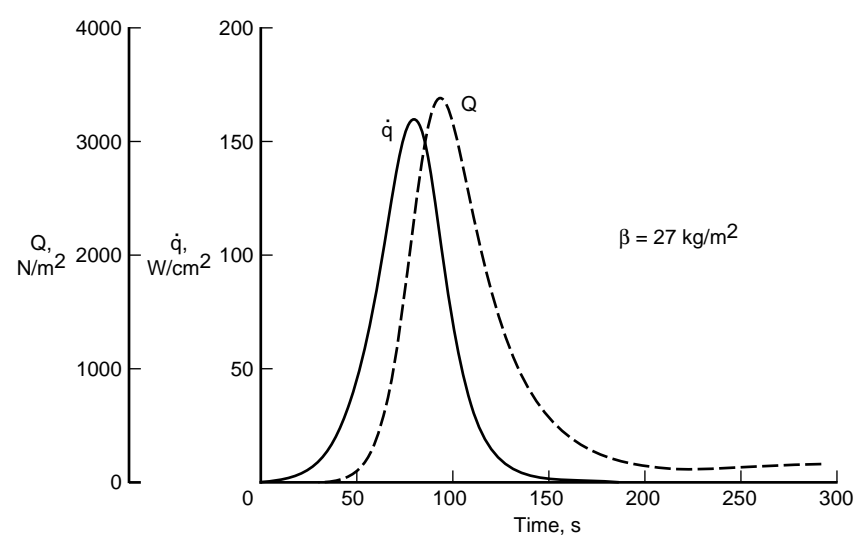

Figure 11. Stagnation-point heat-rate and dynamic pressure profiles.

The nominal entry shown in Figs. 10 and 11 assumes a zero angle-of-attack entry interface orientation, mean atmosphere without wind, and no error in the center-of-gravity position, mass properties, or aerodynamic modeling. Figure 12 presents the total angle-of-attack history for a similar entry initiated with a 90-degree angleof-attack. As shown, total angle-of-attack is damped below 10 degrees within the first 50 sec of atmospheric flight (by $76 \mathrm{~km}$ altitude) and continues to decrease as the dynamic pressure $(Q)$ builds (see Fig. 11). Thus, although high angles-of-attack may occur early in the mission, the Microprobe aeroshells possess sufficient aerodynamic stability to provide passive re-orientation while in the upper atmosphere.

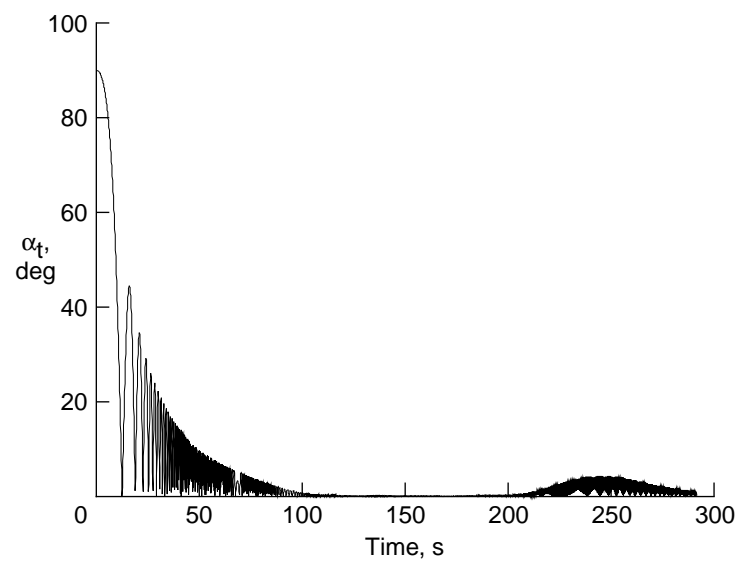

Figure 12. Mars Microprobe total angle-ofattack profile, initial 90-degree angle-of-attack.

This hypersonic re-orientation issue is discussed further in the final section of this paper.

In addition to demonstrating the hypersonic re-orientation capability of the Microprobe aeroshell, Fig. 12 also demonstrates that statically stable flight can be maintained passively throughout EDI. In fact, for this case, the angleof-attack at impact $\left(\alpha_{t}\right)$ is 1.5 degrees. Note that the presence of the transonic dynamic instability is evident in Figure 12. This phenomena is the cause for the small increase in total angle-of-attack from 225 to 275 sec.

Because of Microprobe's small moments of inertia (see Fig. 2), large angular rates are likely during the entry. This high frequency motion is evident in Fig. 12, particularly when dynamic pressure is large. Pitch and yaw rates as high as $200 \mathrm{deg} / \mathrm{sec}$ and an angle-of-attack oscillation frequency of approximately $5 \mathrm{~Hz}$ are likely near peak $Q$. In comparison, Mars Pathfinder's angular motion is characterized by pitch and yaw rates two orders of magnitude lower in the peak dynamic pressure region and a much lower angle-of-attack frequency [23]. Although Microprobe's angular frequency diminishes as dynamic pressure decreases, an increased frequency occurs during transonic flight as a result of the vehicle's dynamic instability. At impact, the vehicle's pitch and yaw rates are more than 


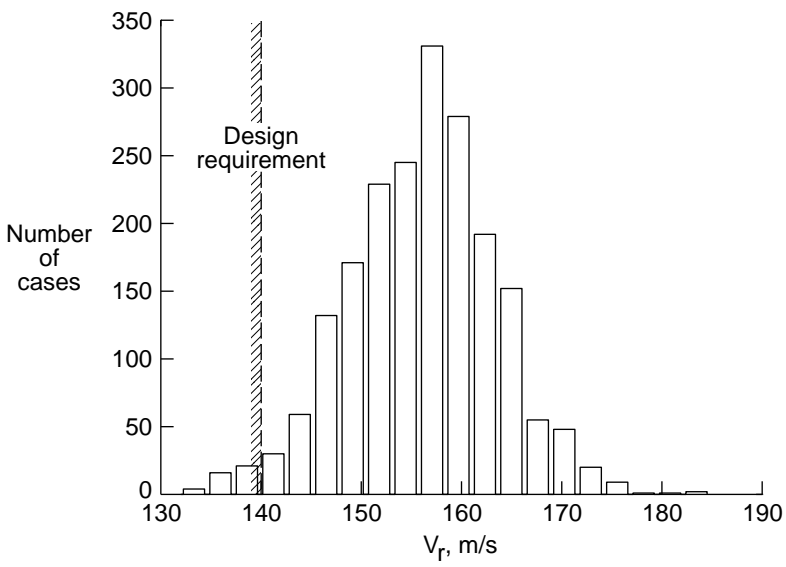

Figure 13. Impact velocity distribution.

an order of magnitude lower than at peak dynamic pressure and the angle-of-attack oscillation frequency is approximately $2.5 \mathrm{~Hz}$.

\section{Monte-Carlo Simulation}

During flight of the Mars Microprobe spacecraft, a combination of off-nominal effects is likely to be encountered. Hence, it is important to statistically assess the effect of combinatorial variations in all of the EDI parameters listed in Table 1. To accomplish this, twothousand off-nominal cases were randomly estimated and simulated in a Monte-Carlo fashion. A $99.7 \%$ probability exists that each random parameter will remain within the $3-\sigma$ uncertainty bounds of Table 1 . In addition to a detailed set of impact conditions, the total angle-of-attack was monitored at discrete points along the heat pulse. Peak deceleration, stagnation-point heatrate, and integrated heat load were also monitored.

Impact Conditions-Histograms of the probable ranges in impact velocity, penetration angle-ofattack and surface incidence angles are shown in Figs. 13 - 15. Monte-Carlo statistics for these impact parameters are tabulated in Table 2. These data indicate that the current set of Microprobe impact requirements are not satisfied in a $3-\sigma$ sense. In particular, the $3-\sigma$ low impact velocity criteria $(140 \mathrm{~m} / \mathrm{s})$ and the $3-$ $\sigma$ high penetration incidence angle (20 degrees)

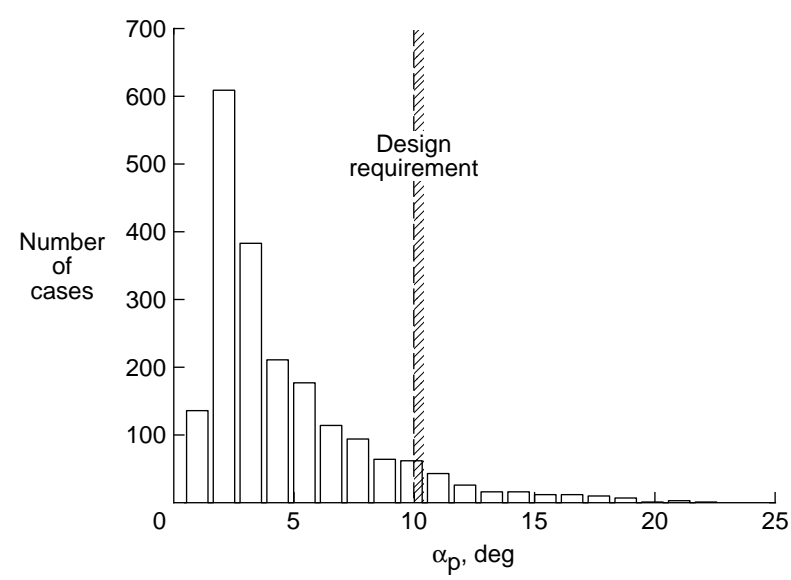

Figure 14. Penetration angle-of-attack distribution.

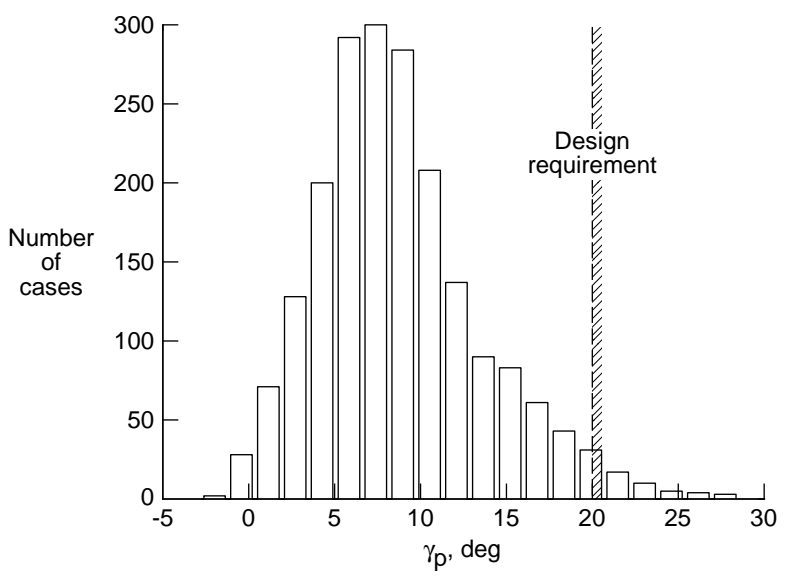

Figure 15. Penetration incidence angle distribution.

Table 2. 6-DOF Mars Microprobe MonteCarlo analysis results.

\begin{tabular}{|l|cc|}
\hline \hline \multicolumn{1}{|c|}{ EDI Parameter } & $\begin{array}{c}\text { Mean } \\
\text { Value }\end{array}$ & $\begin{array}{c}3-\sigma \\
\text { Variance }\end{array}$ \\
\hline Impact velocity, $V_{r}, \mathrm{~m} / \mathrm{s}$ & 156.1 & \pm 22.0 \\
Pen. angle-of-attack, $\alpha_{p}, \mathrm{deg}$ & 4.6 & +14.7 \\
Pen. incidence angle, $\gamma_{p}, \mathrm{deg}$ & 8.7 & \pm 14.4 \\
Impact Mach number, $\mathrm{km}$ & 0.65 & \pm 0.09 \\
Impact time, sec & 298.0 & \pm 29.8 \\
Impact latitude, deg & -74.7 & \pm 1.7 \\
Impact longitude, deg & 148.0 & \pm 1.1 \\
& & \\
Peak $\dot{q}$, W/cm ${ }^{2}$ & 154.1 & \pm 11.9 \\
Peak deceleration, Earth g's & 12.4 & \pm 1.6 \\
Integrated heat load, J/cm ${ }^{2}$ & 6875. & \pm 416.7 \\
& & \\
Peak $\dot{q}$ angle-of-attack, $\alpha_{t}, \mathrm{deg}$ & 13.1 & +27.0 \\
Peak Q angle-of-attack, $\alpha_{t}, \mathrm{deg}$ & 7.8 & +4.2 \\
\hline \hline
\end{tabular}




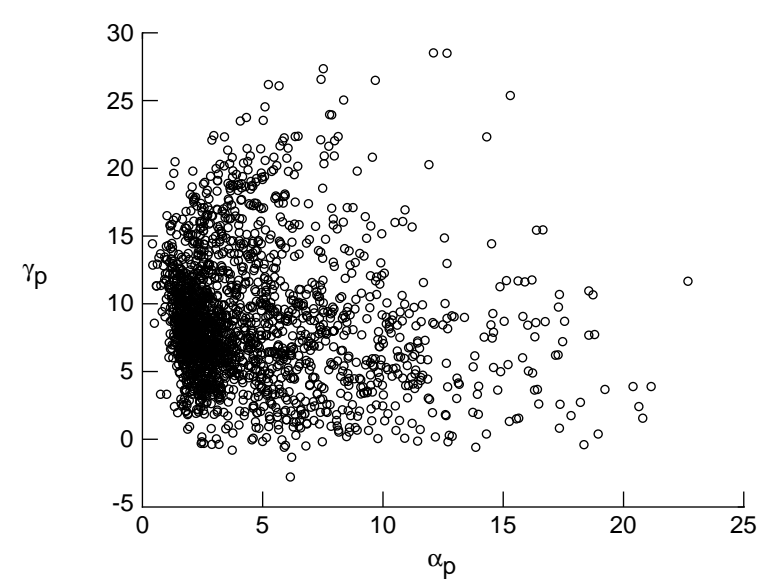

Figure 16. Penetration angles dispersion.

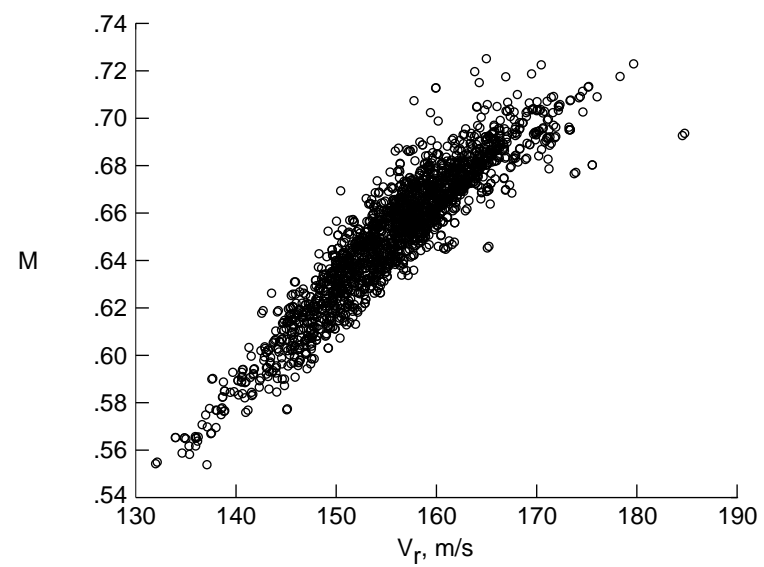

Figure 17. Impact Mach number and velocity dispersion.

are mildly violated. Note that these two criteria are currently satisfied to a $2-\sigma$ probability level. While a small increase in ballistic coefficient could be used to adjust the impact velocity range, such an increase is not recommended as this would only exacerbate the penetration incidence angle problem (see Fig. 8).

Distributions of the significant impact parameters are shown in Figs. 16-19. The two penetration angles show a significant degree of clustering for $\alpha_{p} \leq 4.0$ degrees and $2.0 \leq \gamma_{p} \leq 13.0$. Note that the variation exhibited in Fig. 17 between impact velocity and Mach number is a result of atmospheric temperature variability.

The Microprobe impact footprint is presented in Fig. 19. This footprint should bear some resem-

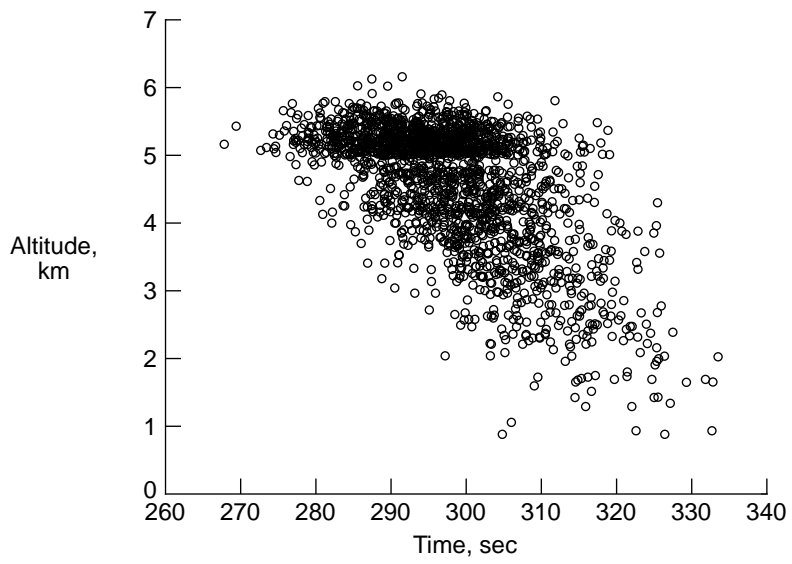

Figure 18. Impact altitude and time dispersion.

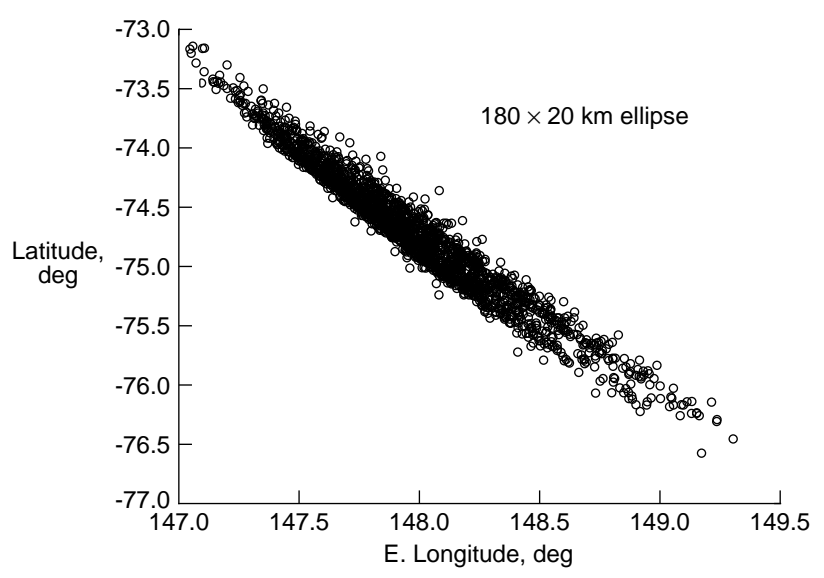

Figure 19. Impact footprint.

blance to the Mars 98 Lander footprint, since both spacecraft approach Mars on the same interplanetary trajectory. As a result of Microprobe's lower ballistic coefficient, the range of impact sites shown in Fig. 19 does not extend as far southeast as the Mars 98 Lander footprint. However, Microprobe's 180 x $20 \mathrm{~km}$ ellipse is similar in downrange and larger in crossrange (Mars 98 Lander is actively controlled) than the predicted Mars 98 Lander ellipse [29].

Peak stagnation-point heating, integrated heat load, and peak atmospheric deceleration statistics are also presented in Table 2. Histograms of these EDI parameters are presented in Figs. 2022 . The variation in intensity of this aerothermodynamic environment does not currently constrain the mission design space because the 


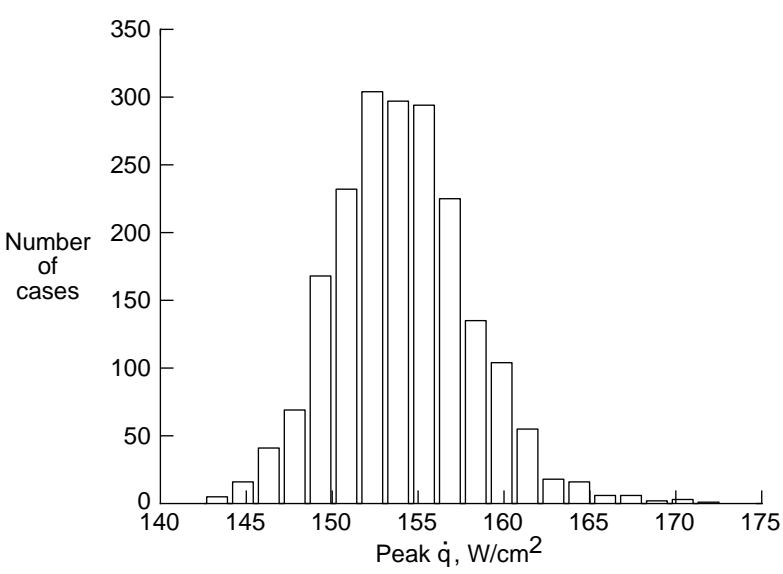

Figure 20. Peak stagnation-point heat rate distribution.

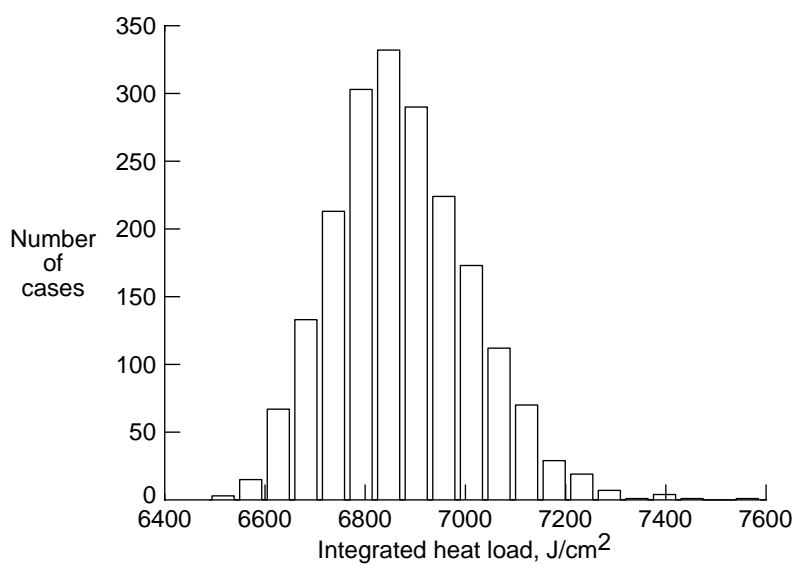

Figure 21. Integrated heat load distribution.

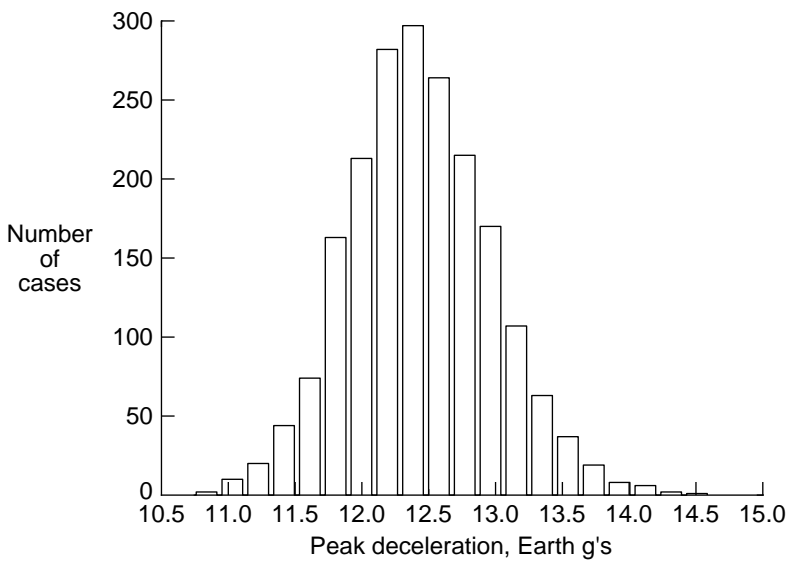

Figure 22. Peak atmospheric deceleration distribution.

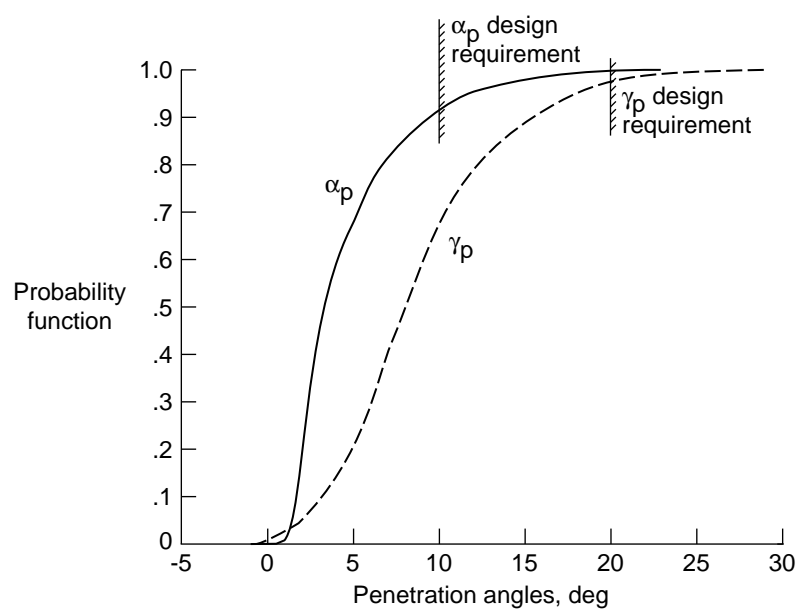

Figure 23. Penetration angles of attack and incidence probability distribution.

heatshield is designed to withstand a peak heat rate of approximately $200 \mathrm{~W} / \mathrm{cm}^{2}$ and an integrated heat load of more than $8550 \mathrm{~J} / \mathrm{cm}^{2}$, based on entry with a $\beta$ of $33.1 \mathrm{~kg} / \mathrm{m}^{2}$. Similarly, the deceleration levels shown in Fig. 22 during atmospheric flight pale in comparison to 30000 Earth g's expected at impact.

As presented in Table 2, the mean angle-ofattack at peak heating and impact do not appear too severe. Since total angle-of-attack is a one-sided function, these variables do not exhibit a Gaussian distribution. Hence, symmetric $3-\sigma$ variances are not listed for angle-ofattack parameters. Instead, probability curves have been generated and are presented in Fig. 23 for the two significant impact angles $\left(\alpha_{p}\right.$ and $\gamma_{p}$ ). These curves give the probability that the angle-of-attack will be below a given value. Hence, from Figs. 23, a 93\% probability (less than $2-\sigma$ ) currently exists that the penetration angle-of-attack will be below 10 degrees. Similarly, there is a $96 \%$ probability (slightly more than $2-\sigma$ ) that the penetration incidence angle will be below 20 degrees. Note that as a result of surface slope variability, the penetration incidence angle may be slightly negative (as much as -2.78 degrees was obtained).

The variances in all of the impact conditions may be reduced through improved modeling of 


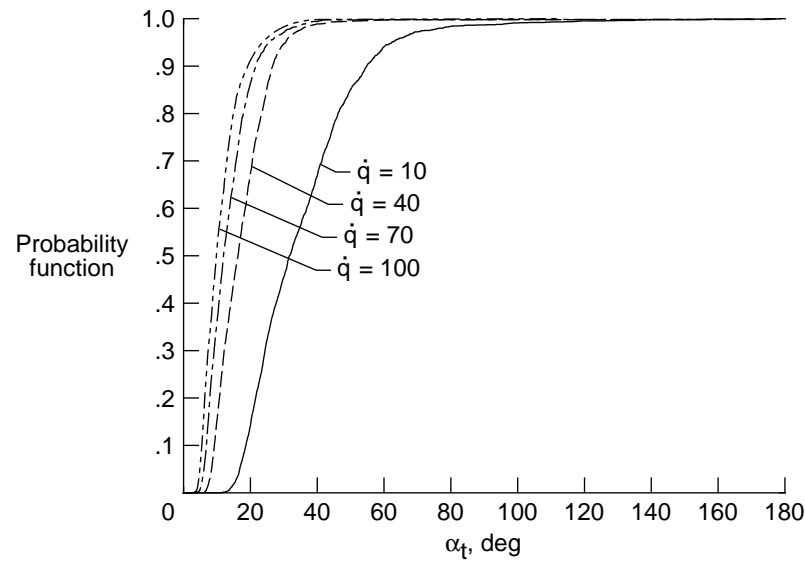

Figure 24. Angle-of-attack probability distribution at several points along the increasing side of heat pulse.

the surface winds, altitude, and slope. For example, most of the impact velocity variance observed in Fig. 13 is a result of surface altitude uncertainty. Similarly, a large percentage of the penetration angle variances presented in Figs. 14 and 15 are the result of the \pm 5degree surface slope currently assumed. The expected range in these penetration angles could also be reduced by moving the center-of-gravity forward.

Hypersonic Re-orientation-Through this analysis, a relatively large angle-of-attack range near peak heating has also been identified. As yet, heating calculations at this flight condition have only been performed at angles of attack below 10 degrees. However, in this analysis, anglesof-attack as high as 45 degrees were obtained in the peak heating region. In fact, the mean angle-of-attack at peak heating (see Table 2) is 13.07 degrees. These results have necessitated the performance of additional afterbody heating analyses.

To bound this aerothermodynamic assessment, angle-of-attack probability functions at discrete points along the increasing side of heat pulse were generated from the present set of MonteCarlo results. This data is shown in Fig. 24. Since EDI is initiated from a random angular orientation $\left(0 \leq \alpha_{t}<180\right.$ degrees $)$, this fig-

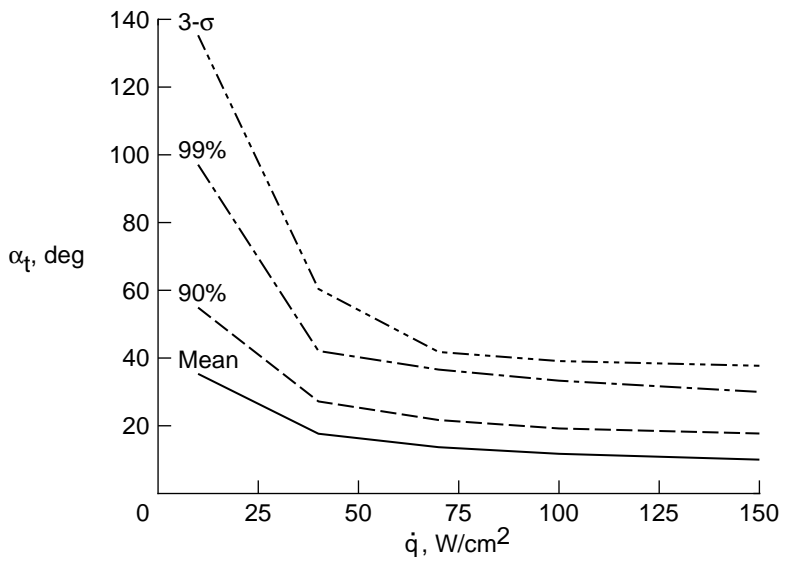

Figure 25. Statistical variation in angle of attack as a function of stagnation-point heat rate.

ure also provides a measure of the aeroshell's hypersonic re-orientation capability. As a result of the aeroshell's aerodynamic stability, this re-orientation occurs relatively early in the atmospheric flight. For example, by the time a $\dot{q}$ of $10 \mathrm{~W} / \mathrm{cm}^{2}$ is achieved, the angle-of-attack range has converged such that there is a $50 \%$ chance that the angle-of-attack will be below 30 degrees. On the nominal trajectory, this heat rate occurs just $28.2 \mathrm{sec}$ past the atmospheric interface at an altitude of $99.1 \mathrm{~km}$.

By the time $40 \mathrm{~W} / \mathrm{cm}^{2}(45.1 \mathrm{sec}, 78.8 \mathrm{~km}$ altitude) is achieved, there is a $70 \%$ chance that the angle-of-attack will be below 20 degrees and a $96 \%$ chance that the angle-of-attack will be below 30 degrees. As $100 \mathrm{~W} / \mathrm{cm}^{2}$ is approached (60.6 sec, $62.8 \mathrm{~km}$ altitude), the probability is $95 \%$ that the angle-of-attack will be below 20 degrees. This information is shown as a function of stagnation-point heat rate in Fig. 25. In this figure, the peak heating region is at 150 $\mathrm{W} / \mathrm{cm}^{2}$. At peak heating, there is a $99 \%$ probability that the angle-of-attack will be below 30.0 degrees and a $90 \%$ probability that the angleof-attack will be below 18.0 degrees.

The vehicle's hypersonic re-orientation capability is largely a function the vehicle's aerodynamic shape and center-of-gravity position. For a given vehicle configuration, the damping provided by the atmospheric forces depends on dy- 
namic pressure, $Q$. Unfortunately, as shown in Fig. 11, peak $Q$ occurs approximately 15 sec past peak $\dot{q}$. Hence, the forces providing this passive angle-of-attack convergence are not at their greatest level until beyond peak heating. In fact, in $97 \%$ of the cases simulated, the angle-of-attack stays below 10-degrees from peak dynamic pressure to Mach 2 (see Fig. 12). Improvements in the hypersonic re-orientation level prior to peak $\dot{q}$ can be achieved by moving the center-of-gravity position forward, reducing the products of inertia, or reducing the angular rates associated with the initial separation maneuver. This is currently the number one issue confronting the EDI team. In an effort to determine the mission impact of this phenomenon, additional afterbody heating analyses are being performed.

\section{Conclusions}

Scheduled for flight in 1999, the New Millennium Mars Microprobe mission will provide the first opportunity for subsurface measurements, including water detection, near the south pole of Mars. Design of the Microprobe aeroshells poses several unique aerodynamic challenges including passive hypersonic re-orientation of an initially tumbling body and stringent stability constraints during a subsonic impact. The criteria used in the selection a 45-degree spherecone forebody with hemispherical afterbody are presented in this paper.

The performance of the Microprobe aeroshell design is then evaluated through the development of a six-degree-of-freedom (6-DOF) aerodynamic database and flight dynamics simulation. Numerous mission uncertainties are quantified and a Monte-Carlo analysis is performed to statistically assess mission performance. Results from this 6-DOF Monte-Carlo simulation demonstrate that, in a majority of the cases (generally $2-\sigma$ ), the penetrator impact conditions are within current design tolerances. In particular, the $3-\sigma$ range of impact velocity is $134-178 \mathrm{~m} / \mathrm{s}$. The $2-\sigma$ high penetration angleof-attack is 12 degrees and the $2-\sigma$ high pene- tration incidence angle is 18 degrees. The Microprobe impact footprint extends $180 x 20 \mathrm{~km}$ with its center at -74.73 degrees South latitude, 147.98 degrees East longitude. Suggestions for improvement are made to enhance Microprobe EDI performance.

In addition, a relatively large angle-of-attack range near peak heating is identified which has necessitated the performance of additional afterbody heating analyses. These afterbody heating analyses are strongly coupled to the hypersonic re-orientation performance derived from the present results. In particular, a 50\% probability exists that the angle-of-attack will be below 30 degrees before a $\dot{q}$ of $10 \mathrm{~W} / \mathrm{cm}^{2}$ is achieved; whereas, a $96 \%$ probability exists that the angle-of-attack will be below 30 degrees before $\dot{q}=40 \mathrm{~W} / \mathrm{cm}^{2}$. As $100 \mathrm{~W} / \mathrm{cm}^{2}$ is approached, there is a $95 \%$ chance that the angle-of-attack will be below 20 degrees. At peak heating, a mean angle-of-attack of 13.07 degrees was obtained and a $90 \%$ probability exists that this parameter will be below 18 degrees.

\section{ACKNOWLEDGMENTS}

The authors are indebted to Eric M. Slimko of the Jet Propulsion Laboratory for providing technical insight and program coordination of the Microprobe EDI design strategy, Scott A. Striepe of NASA Langley Research Center for implementing the eighth-order Runge-Kutta integration technique within POST, and William L. Kleb of NASA Langley Research Center for assistance with the $\mathrm{IAT}_{\mathrm{E}} \mathrm{X}$ document preparation system.

\section{REFERENCES}

[1] Casani, E. and Wilson, B., "The New Millennium Program: Technology Development for the 21st Century," AIAA Paper 96-0696, Jan. 1996.

[2] Bourke, R., Golombek, M., Spear, A., and Sturns, F., "MESUR and Its Role in an Evolutionary Mars Exploration Program," IAF Paper 92-0509, Oct. 1992. 
[3] Hubbard, G., Wercinski, P., Sarver, G., Hanel, R., and Ramos, R., "A Mars Environmental Survey (MESUR) - Feasibility of a Low Cost Global Approach," IAF Paper 91-0432, Oct. 1991.

[4] Powell, G. and Gavit, S., "New Millennium Mars Microprobe Mission and System Specifications," MMP/Spec-02, JPL-D-13752, Sept. 1996.

[5] Uselton, B. L., Shadow, T. O., and Mansfield, A. C., "Damping in Pitch Derivatives of 120 and 140 Deg Blunted Cones at Mach Numbers 0.6 through 3.0," AEDC TR-70-49, 1970.

[6] Anon., "Experimental Pitch Damping Derivatives for Candidate Viking Entry Configurations at Mach Numbers 0.6 through 3.0," NASA TR-3709005, Martin Marietta Corp., Denver, CO, June 1970.

[7] Weinberg, S. A., "Final Data Report - Pioneer Venus Static and Dynamic Transonic Wind Tunel Tests," Tech. Rep. 9154-TDM-75-013, July 1975.

[8] Walberg, G., "A Review of Aerobraking for Mars Missions," IAF Paper 88-196, Oct. 1988.

[9] Engelund, W., Gnoffo, P., Cruz, C., Braun, R., and Weilmuenster, K., "Aerodynamic Characteristics of the Mars Pathfinder Atmospheric Entry Configuration," NASA TM in preparation.

[10] Wakefield, R. and Pitts, W., "Analysis of the Heat-Shield Experiment on the Pioneer-Venus Entry Probes," AIAA Paper 80-1494, July 1980.

[11] Moss, J., "Advancements in Aerothermodynamics in Support of the Galileo Probe," Proceedings of the 13th International Symposium on Space Technology and Science, Tokyo, Japan, 1982.

[12] Seiff, A., Reese, D. E., Sommer, S. C., Kirk, D. B., Whiting, E. E., and Niemann, H. B., "PAET, An Entry Probe Experiment in the Earth's Atmosphere," Icarus, Vol. 18, No. 4, Apr. 1973, pp. 525563.

[13] Sammonds, R. I., "Dynamics of High Drag Probe Shapes at Transonic Speeds," NASA TN D-6489, Sept. 1971.

[14] Mitcheltree, R., Moss, J., Cheatwood, F., Greene, F., and Braun, R., "Aerodynamics of the Mars Microprobe Entry Vehicles," 15th AIAA Applied Aerodynamics Conference, Atlanta GA, June 1997.

[15] Gnoffo, P., Weilmuenster, K., Braun, R., and Cruz, C., "Influence of Sonic Line Location on Mars Pathfinder Probe Aerothermodynamics," Journal of Spacecraft \&s Rockets, Vol. 33, No. 2, Mar.-Apr. 1996, pp. 169-177.

[16] Nichols, J. O. and Nieremgarten, E. A., "Aerodynamics Characteristics of Blunted Bodies," JPL TR 32-677, 1964.

[17] Brooks, J. D., "Some Anomolies Observed in Wind Tunnel Tests of a Blunt Body at Transonic and Supersonic Speeds," NASA TN D-8237, June 1976.
[18] Vatsa, V. N., Turkel, E., and Abolhassani, J. S., "Extension of Multigrid Methodology to Supersonic/Hypersonic 3-D Viscous Flows," NASA CR 187612, Aug 1991.

[19] Slimko, E., Winchenbach, G., and Lipnitski, Y., "Transonic Dynamic Stability Investigations of a 45 Degree Sphere-Cone with Hemispherical Afterbody," 15th AIAA Applied Aerodynamics Conference, Atlanta GA, June 1997.

[20] Winchenbach, G. and Hathaway, W., "Mars Microprobe Free Flight Data Analysis," Aeroballistic Research Facility Ballistic Spark Range, Wright Laboratory, Eglin Air Force Base, Aug 1996.

[21] Cheatwood, F. and Mitcheltree, R., "Aerodynamic Database for Mars Microprobe," NASA TM in preparation.

[22] Brauer, G., Cornick, D., and Stevenson, R., "Capabilities and Applications of the Program to Optimize Simulated Trajectories," NASA CR 2770, Martin Marietta Corp., 1977.

[23] Braun, R., Powell, R., Engelund, W., Gnoffo, P., Weilmuenster, K., and Mitcheltree, R., "Mars Pathfinder Six Degree-of-Freedom Entry Analysis," Journal of Spacecraft \& Rockets, Vol. 32, No. 6, Nov.-Dec. 1995, pp. 993-1000.

[24] Spencer, D. and Braun, R., "Mars Pathfinder Atmospheric Entry: Trajectory Design and Dispersion Analysis," Journal of Spacecraft $\&$ Rockets, Vol. 33, No. 5, Sept.-Oct. 1996, pp. 670-676.

[25] Spear, A., Freeman, D., and Braun, R., "Mars Pathfinder Status at Launch," IAF Paper 96Q.3.02, Oct. 1996 .

[26] Kallemeyn, P., Spencer, D., Vaughan, R., and Helfrich, C., "The Mars Pathfinder Navigation System," AIAA Paper 96-3656, July 1996.

[27] Fehlberg, E., "Classical Fifth-, Sixth-, Seventh-, and Eighth-Order Runge-Kutta Formulas with Stepsize Control," NASA TR R-287, June 1968.

[28] Zurek, R. W., "Recommended Environments for MSP98 Lander," IOM 081296, Jet Propulsion Laboratory, Aug 1996.

[29] Spencer, D., "Personal communication," Jet Propulsion Laboratory, Sept., 1996. 